Journal of Advanced Research in Materials Science

\title{
Performance and Emission of Palm Oil Methyl Ester Biodiesel with Various Additives in Direct Injection Diesel Engine
}

\author{
Cheah Yi Linn ${ }^{1}$, Mohd Radzi Abu Mansor ${ }^{1,}{ }^{*}$, Zul Ilham $^{2}$ \\ 1 Department of Mechanical Engineering, Faculty of Engineering and Built Environment, Universiti Kebangsaan Malaysia, UKM Bangi 43600, \\ Selangor, Malaysia \\ 2 Institute of Biological Sciences, Faculty of Sciences, University of Malaya, 50603 Kuala Lumpur, Malaysia
}

\section{ABSTRACT}

Biodiesel can be used as an alternative fuel for the diesel engine and have a good combustion characteristic because of their longchain hydrocarbon structure. However, biodiesel possesses few disadvantages such as lower heating value, higher viscosity, higher density and will contribute to several engine problems such as low atomization during injection and carbon deposit formation. There are many types of additives on the market but the extent of the additives on engine performance is unknown and only several researches has been done in studying the performance, emissions and fuel consumption of $100 \%$ palm oil methyl ester (B100 biodiesel). In this study, there is five type of B100 biodiesel. The objectives of this research are to identify individual composition in each biodiesel samples, such as the identification of additives and fatty acids methyl esters using gas chromatography (GC-FID). The experimental measurements of density, viscosity and calorific value of B100 biodiesel were conducted. The results showed that a blend of biodiesel with diethyl ether and $n$-butanol has the closest calorific value to fuel diesel followed by the combination additives of ethanol, butanol and methyl pyrrolidone. Engine performance and emission were also investigated by determining the BSFC, BTE and CO, HC, and NOx gas emissions by simulation using CONVERGE CFD software based on single-cylinder, direct injection YANMAR TF90 diesel engine parameters. Performance results show that the combination of diethyl ether and $n$-butanol as an additive with crude palm oil will give a higher brake power and lower NOx and brake specific fuel consumption among all samples. The emission studies revealed that the addition of $\mathrm{n}$-butanol additive can reduce carbon monoxides (CO), nitrogen oxides (NOx), particulate matter (PM) emission while diethyl ether can improve the spray characteristics when it blends with B100 biodiesel due to its low density and viscosity.

Keywords:

Biodiesel; B100; additives; heat release rate

Copyright @ 2020 PENERBIT AKADEMIA BARU - All rights reserved

\section{Introduction}

Diesel engines are widely used in industries and transportation sectors. The increasing of energy demand in transportation sectors along with the limitation of natural resources of fossil fuels and their negative effects on environments are the main motivations for researchers to search for an alternative fuel. The search for an alternative fuel for diesel engines has intensified in recent years with the imminent depletion of fossil fuel in the future. Among all the fuels, biodiesel plays an important role because it is classified as green and renewable energy derived from renewable

\footnotetext{
* Corresponding author.

E-mail address: radzi@ukm.edu.my
}

https://doi.org/10.37934/arms.72.1.114 
biomass resources which is less toxic and biodegradable [1]. Biodiesel as an alternative fuel in a diesel engine without engine modification.

Exhaust emissions from engine combustion such as nitric oxide $\left(\mathrm{NO}_{\mathrm{x}}\right)$, carbon monoxide (CO), carbon dioxide $\left(\mathrm{CO}_{2}\right)$ and hydrocarbons $(\mathrm{HC})$ are the major contributor to high air pollution greenhouse effect and cause a shift in the climate system [2] . Therefore, alternative fuel has become very attractive in this era. Many researchers noted that biodiesel used in diesel engines can promote reduce the exhaust emissions [3-4]. Palm oil methyl ester (PME) fuel is one a kind of biodiesel fuel which is known as the best biodiesel in Malaysia [5]. Several studies found out that PME has been proven to be a good choice to help solving the global warning air pollution [6]. It contains high oxygen amount $10 \%$ to $12 \%$ by weight which can significantly contribute to complete combustion and can be used in diesel engine directly without major modification [7]. Nonetheless, the major disadvantages of biodiesel are its low cetane number, high viscosity, high density and extremely high flash point that may cause some operability problems on poor atomization of fuel spray and incomplete combustion where the combustion suddenly deteriorates in chamber [8]. Therefore, the most suitable and economical way to improve palm oil biodiesel and engine performance is adding with appropriate use of additives. This technology is safely adopted in diesel engine are widely researched and developed [9-10].

Additives mixed in biodiesel fuel blends act as an oxygenated antioxidant. With the help of additives, biodiesel properties can be enhanced and to improves combustion characteristics, lubricity and reduces exhaust emissions, reduction in exhausts emissions. The additives usage also has some limitations, such as reduced ignitability and cetane number [11] which may result in increased emissions of unburned hydrocarbons. Therefore, additives were introduced in low portions. A small portion of ethanol (E) as an additive can effectively reduce exhaust emission and reduce the lubricity of the fuel [12]. However, the drawbacks of ethanol use include a low heating value due to the high oxygen content which may decrease the brake thermal efficiency of the engine. In the past few year studies have shown that $n$-butanol is emerged to have the highest potential to function as biodiesel additions and can be used easily as additives. N-butanol (BU) has the properties which make it a suitable ethanol replacement or addition as it has a higher energy content in addition to a significant improvement in combustion engine. $\mathrm{N}$-butanol has a lower ignition temperature. Therefore, it can be ignited easier when burned in diesel engine. It has straight chain with $\mathrm{OH}$ group and has lower hydrophilic compared to methanol and ethanol [13-14]. High cetane number, good miscibility and higher heating value attract many researchers to consider $n$-butanol as an additive to biodiesel. A study from Iftikhar et al., [15] shows that it has lower emission such as carbon monoxide (CO), oxides of nitrogen (NOx) and smoke opacity. However, unburned hydrocarbon ( $\mathrm{HC}$ ) emission was found to be slightly increased. Diethyl ether (DEE) is also a suitable additive that can be used with biodiesel fuels for diesel engines because it is a cetane improver besides an oxygenated fuel [16]. The presence of oxygen plays an important role to reduce PM and other harmful emissions from diesel engines by improving the performance and combustion characteristics. However, NOx emissions can be reduced in some cases and it may increase depending on the engine operating conditions [17]. To the best of the authors' knowledge, none of the previous researchers investigated the effect of the combination of two different additives on the biodiesel fuel properties.

This work is to identify the composition and additional content found in biodiesel using gas chromatography (GC-FID) and figure out the best additives by concerning about the fuel quality improvements of the palm methyl ester fuel. In addition, the experimental thermal physical property tests of the biodiesel were performed in this study including density, viscosity and calorific value which were evaluated under the ASTM 6751 standard. The simulation was conducted using Converge CFD software based on the direct injection YANMAR TF90 diesel engine parameter. Moreover, the 
results obtained from this method are more focused on features combustion such as pressure in the cylinder, heat release rate, and exhaust emissions during the burning process to identify the influence of different additives used in biodiesel. The optimization of the best solution of additives used was identified from the results.

\section{Methodology}

Gas chromatography is carried out to study of separation of mixtures and to identify unknown components in biodiesel sample. All biodiesel sample were simulated to analyse their combustion characteristics and emission. The combustion characteristics results from the simulation were validated with the experimental results. Grid independence test and emission tests were conducted to further analyse the biodiesel.

\subsection{Gas Chromatography (GC-FID) and Thermophysical Properties of Biodiesel}

The chemical composition of the biodiesel samples was measured using gas chromatography with flame ionization detection (GC-FID) to identify and quantify the composition for the five biodiesels. Biodiesel sample are mixed with $1 \mathrm{ml}$ of methanol as a solvent to ensure that the intensity value of GC does not exceed the prescribed limit. This methanol content is mixed into biodiesel sample and left for 5 minutes for isolation purposes. A layer was formed and separated using a syringe and the liquid mixture was stored as $1 \mathrm{ml}$ to be the sample in GC analysis. The fatty acid methyl ester (FAME) profiles of the biodiesel samples were being analyse. Palmitic acid content is the highest fatty acid content and this indicates that biodiesel sample are Palm oil methyl ester (PME). The fatty acid content plays a very important role during combustion. These fatty acids consist of two categories, namely saturated acids and unsaturated acids. Lauric, palmitic, myristic and stearic acids are considered as saturated acids, where they do not contain any twin bonds between carbon atoms. Meanwhile, oleic acid, linoleic and linolenic acid are unsaturated acids that contain twin bonds. Exhaust emissions such as $\mathrm{HC}, \mathrm{NOx}, \mathrm{CO}, \mathrm{CO} 2$ and others depend on the composition of the fatty acids found in biodiesel. If the presence of excess linoleic fatty acid in biodiesel can lead to NOx formation and indicate low engine efficiency [18]. Besides, experimental works were done to identify the thermophysical properties such as density, viscosity and calorific value. Table 1 shows the thermophysical properties and chemical composition of the biodiesels. From this study found out that BD3 is modified from BD1 with the addition of $n$-butanol. Whereas, BD4 is a modification of BD2 with the addition of n-methyl pyrrolidone.

Table 1

Thermophysical properties and chemical composition of the biodiesels

\begin{tabular}{lllll}
\hline $\begin{array}{l}\text { Biodiesel } \\
\text { sample }\end{array}$ & $\begin{array}{l}\text { Density, } \\
\mathrm{kg} / \mathrm{m}^{3}\end{array}$ & $\begin{array}{l}\text { Viscosity, } \\
\mathrm{kg} / \mathrm{ms}\end{array}$ & $\begin{array}{l}\text { Calorific } \\
\text { Value, } \mathrm{kJ} / \mathrm{kg}\end{array}$ & \begin{tabular}{l} 
Chemical composition \\
\hline BD1
\end{tabular} \\
784 & 5.52 & 37,124 & PME + Diethyl ether (DEE) \\
BD2 & 834 & 7.94 & 39,264 & PME + Ethanol (E) + n-butanol (BU) \\
BD3 & 803 & 6.48 & 39,812 & PME + Diethyl ether + n-butanol \\
BD4 & 819 & 6.08 & 38,895 & PME + Ethanol + n-butanol + n-methyl pyrrolidone (PY) \\
BD5 & 821 & 9.35 & 37,921 & PME + Acetone (ACE) \\
\hline
\end{tabular}




\subsection{Simulation of Biodiesel Combustion Characteristics and Emission}

Simulation of combustion engine is conducted using CONVERGE CFD software based on single cylinder YANMAR TF90 diesel engine parameters. In order to study on the combustion characteristics in the chamber, the process such as in-cylinder pressure, heat release during combustion were analysed. The engine model is drawn in Figure 1 and the model parameter of the engine and injection system based on the real engine parameter for the YANMAR TF90 direct injection diesel engine are extracted from the study of Ibrahim et al., [18] as shown in Tables 2 and 3. As for boundary conditions, the wall and head of the cylinder are the fixed boundaries that do not experience any movement during the whole combustion process. Meanwhile, the piston was set as moving boundary throughout the process of simulation with motion. On the other hand, the condition of the temperature on the surface of piston, cylinder wall and head were also set to $403 \mathrm{~K}, 363 \mathrm{~K}$ and $319 \mathrm{~K}$ respectively. This input data is used to avoid increasing the temperature distribution of the combustion engine model to go extreme and becomes more precise. The injection model used in this simulation was Kelvin-Heimholtz (KH) and Reyleigh-Taylor (RT).

Table 2

Engine specifications [19-20]

\begin{tabular}{ll}
\hline Parameters & Specifications \\
\hline Engine model & YANMAR TF90 \\
Bore $(\mathrm{m}) \times$ Stroke $(\mathrm{m})$ & $0.085 \times 0.087$ \\
Connecting rod length $(\mathrm{m})$ & 0.13 \\
Piston bowl diameter $(\mathrm{m})$ & 0.0463 \\
Piston bowl depth $(\mathrm{m})$ & 0.016 \\
\hline
\end{tabular}

Table 3

Engine operating injection specification [19-20]

\begin{tabular}{ll}
\hline Parameters & Specifications \\
\hline Number of nozzles (orifice $x$ diameter) $(\mathrm{mm})$ & $4 \times 0.22$ \\
Injection pressure (MPa) & 19.613 \\
Injection duration $\left({ }^{\circ} \mathrm{CA}\right)$ & 16 \\
Injection timing $\left({ }^{\circ} \mathrm{CA} \mathrm{BTDC}\right)$ & -18 \\
\hline
\end{tabular}

Ambient atmospheric pressure forces the air-fuel mixture through the open intake valve into the cylinder to fill the low-pressure area created by the piston movement. As fuel was injected, the combustion chamber was filled air. Therefore, the temperature and air pressure in the cylinder are set to $300 \mathrm{~K}$ and $101 \mathrm{kPa}$ as the initial conditions. The simulation time used is based on the rotation angle of the crank for one cycle of engine movement. It begins when the intake valve closes (IVC) at $-168^{\circ} \mathrm{CA}$ BTDC and ends when the exhaust valve opens (EVC) at $138^{\circ} \mathrm{CA}$ ATDC. SAGE combustion model is used for the present simulation in this closed-system chamber. The SAGE model runs in parallel with flow solver which speed up the overall simulation. With suitable reactions mechanism, SAGE can be used to analyse different combustion phenomenon. In this simulation, thermodynamic data, gas transport data and mechanism data were obtained from Lawrence Livermore State Laboratory (LLNL). Besides, the process of reduction mechanism is required to reduce the number of the chemical reaction in biodiesel to simplify and speed up the simulation process. Meanwhile, to identify the emissions of NOx from combustion, Zeldovich NOx model was used. As for turbulent model, LES model was used to ensure a better and more accurate combustion results. 


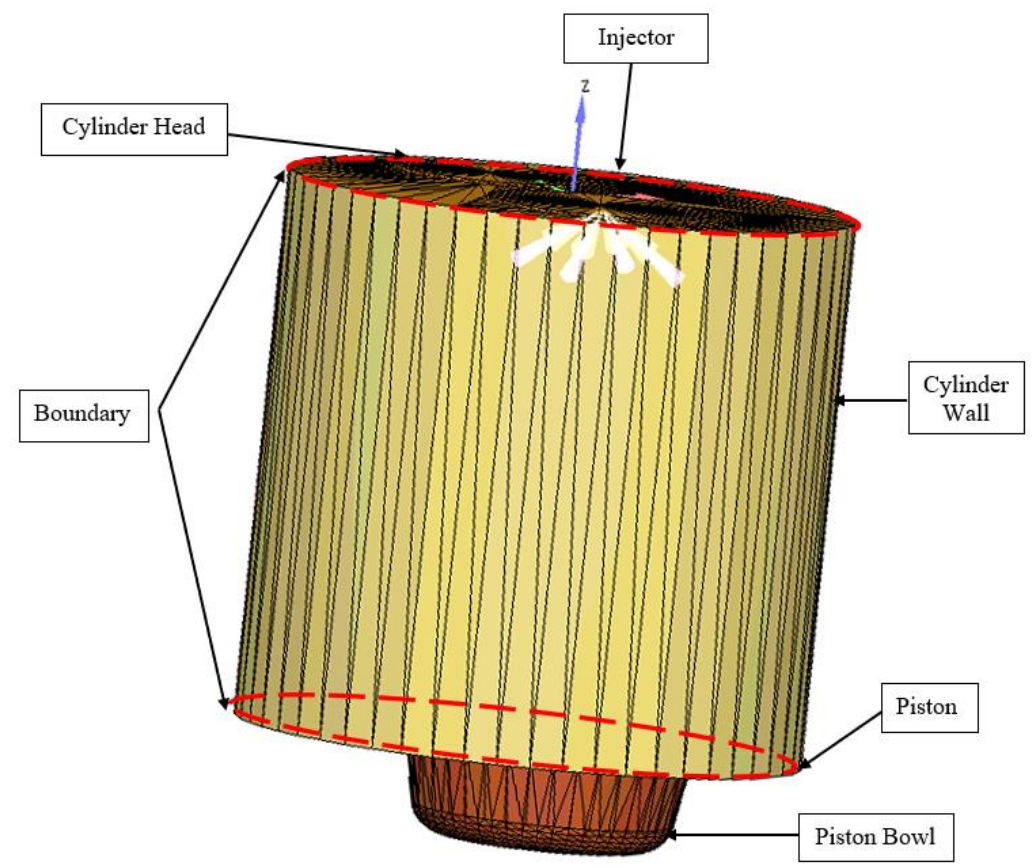

Fig. 1. YANMAR TF90 piston model

\subsection{Validation of Simulation Results Through Experiment}

The numerical results obtained from CONVERGE CFD are validated using the experimental data on YANMAR TF90 engine at the same operating conditions. All the engine and simulation parameters were kept the same throughout the whole experiment. Figure 2 represents the comparison of incylinder peak pressure between numerical and experimental data of BD3 with additive diethyl ether and $\mathrm{n}$-butanol. The three main parameters were considered for validation and the parameters are in-cylinder peak pressure, $\mathrm{CO}_{2}$ and $\mathrm{CO}$ emission.

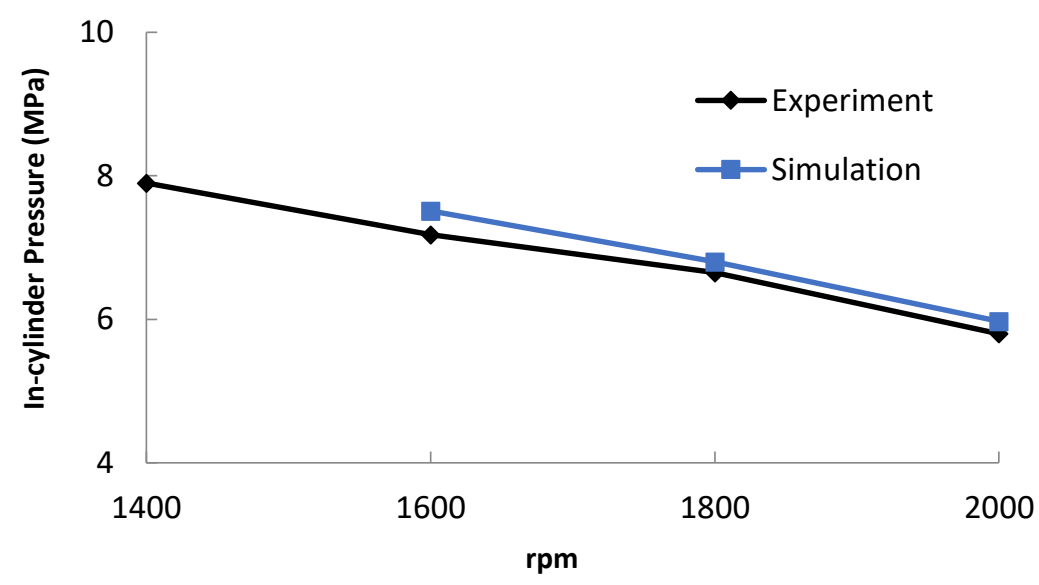

Fig. 2. Comparison of in-cylinder peak pressure from simulations and experiments for BD3

In comparing the in-cylinder peak pressure of the experiment and simulation data, the smallest error observed is around $2.25 \%$ for 1800 RPM whereas the highest percentage error is $4.59 \%$ for 1600 RPM as shown in Table 4. In real engine condition, loss of air may be the result of wear and tear between the piston and the cylinder liner which may cause reduce the pressure of in-cylinder. Hence, 
the peak pressure inside the cylinder from the experiment data were slightly lower than simulation data and differences is small. Thus, the situation clearly indicates that chemical and physical properties of the biodiesel in real condition significantly influence the simulation results. The simulation results are highly dependent on the kinetic reaction of the database used in CONVERGE CFD.

Table 4

Percentage error at peak pressure with various engine speed

\begin{tabular}{ll}
\hline Engine speed (RPM) & Percentage error at peak pressure (\%) \\
\hline 1600 & 4.59 \\
1800 & 2.25 \\
2000 & 2.93 \\
\hline
\end{tabular}

Figure 3 shows the comparison of $\mathrm{CO}$ and $\mathrm{CO}_{2}$ emissions of $\mathrm{BD} 3$ between simulation and experiment data. The average $\mathrm{CO}$ and $\mathrm{CO}_{2}$ emissions for $\mathrm{BD} 3$ were calculated from simulation results and compared with the experiment data. The comparison results show that $\mathrm{CO}_{2}$ emissions are insignificantly different. Meanwhile, there was a slight difference on $\mathrm{CO}$ emissions especially at high engine speeds. Both the results showed that the simulation accuracy of the experiment data has a maximum error less than $10 \%$. Therefore, the simulation model is in accordance with the experimental data which can provide a closer information that corresponds to experiment data such as its combustion characteristics and emissions for further study. After successfully validating the results, other simulations will be performed by using the same engine parameters, where the performance, combustion characteristics and engine emissions will be further studied.
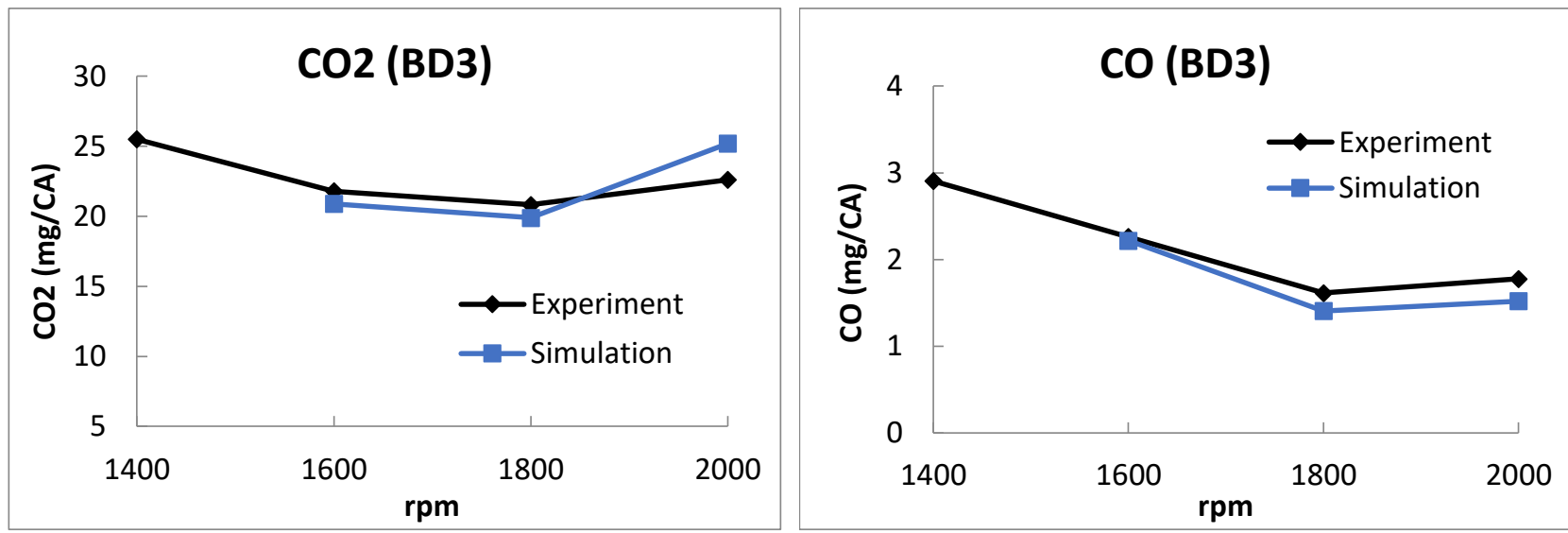

Fig. 3. Comparison of emissions from simulations and experiments for BD3

\section{Results}

\subsection{Grid Independence Test}

Grid independence test was performed to determine the appropriate grid size for use for meshing. This analysis aims to eliminate any unnecessary meshing to improve the simulation results. Figure 4 shows the in-cylinder pressure graph of BD3 using different grid sizes of $0.003 \mathrm{~m}, 0.004 \mathrm{~m}$, $0.005 \mathrm{~m}$ and $0.006 \mathrm{~m}$ at engine speed of $1600 \mathrm{RPM}$. The in-cylinder pressure is compared with the experiments results to determine the most appropriate grid size to use. Results from the comparison found out that grid size of $0.004 \mathrm{~m}$ grid has the smallest error value of $4 \%$ at peak pressure. The best 
model for simulation is to have the smallest error value compared with the experiment data. By considering the simulation duration, Table 4 indicates that $0.004 \mathrm{~m}$ is the most suitable grid size as compared to $0.003 \mathrm{~m}$ since they are almost convergent with each other and also due to small grid size of $0.003 \mathrm{~m}$ will lead to larger computer capacity requirement and thereby required a longer simulation time. Hence, grid size of $0.004 \mathrm{~m}$ had proven a better result for further simulation.

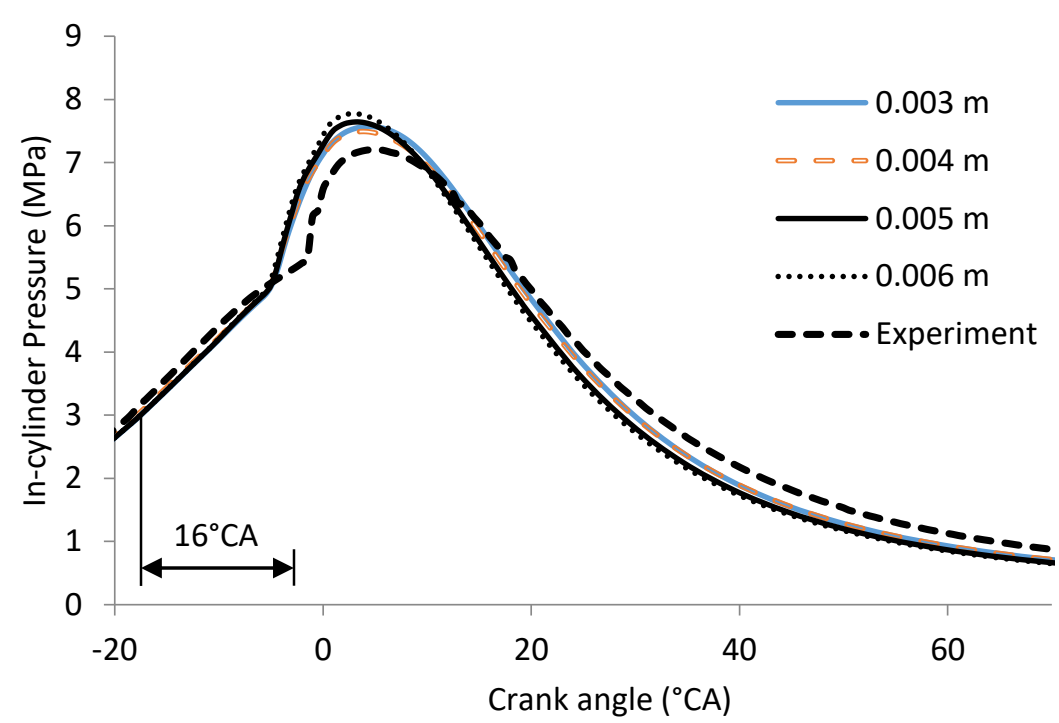

Fig. 4. In-cylinder pressure of BD3 from the simulation with different grid sizes when the engine is running at 1600 RPM compared with the experiment

Table 4

Comparison of percentage error and simulation duration from the in-cylinder pressure with different grid sizes

\begin{tabular}{lll}
\hline Grid size & Percentage error at peak pressure (\%) & Simulation duration $(\mathrm{min})$ \\
\hline 0.003 & 5.148 & 1569 \\
0.004 & 4.079 & 985 \\
0.005 & 6.145 & 664 \\
0.006 & 8.022 & 454 \\
\hline
\end{tabular}

\subsection{Effect of Biodiesel with Additives on Combustion Characteristics}

\subsubsection{Sauter mean diameter (SMD)}

Sauter mean diameter (SMD) is an expression used to describe the characteristics of injection form and distribution of fuel drop size. SMD distribution is a key parameter in analysing the injection characteristics associated with combustion and discharge characteristics in the engine. Figure 5 shows the SMD graph of PME with different additives at engine speed of 1600 RPM. The average SMD of the mixture indicates that the additive which contained diethyl ether forms a larger droplet size of fuel compare to others. However, there is a small difference can be seen from the graph when the piston moves from TDC to BDC. N-butanol has a much lower viscosity and higher evaporation which can induce better fuel extraction. Therefore, additives with $n$-butanol the disintegration is implemented much easier, and as expected the SMD of containing $n$-butanol demonstrates a lower SMD. 


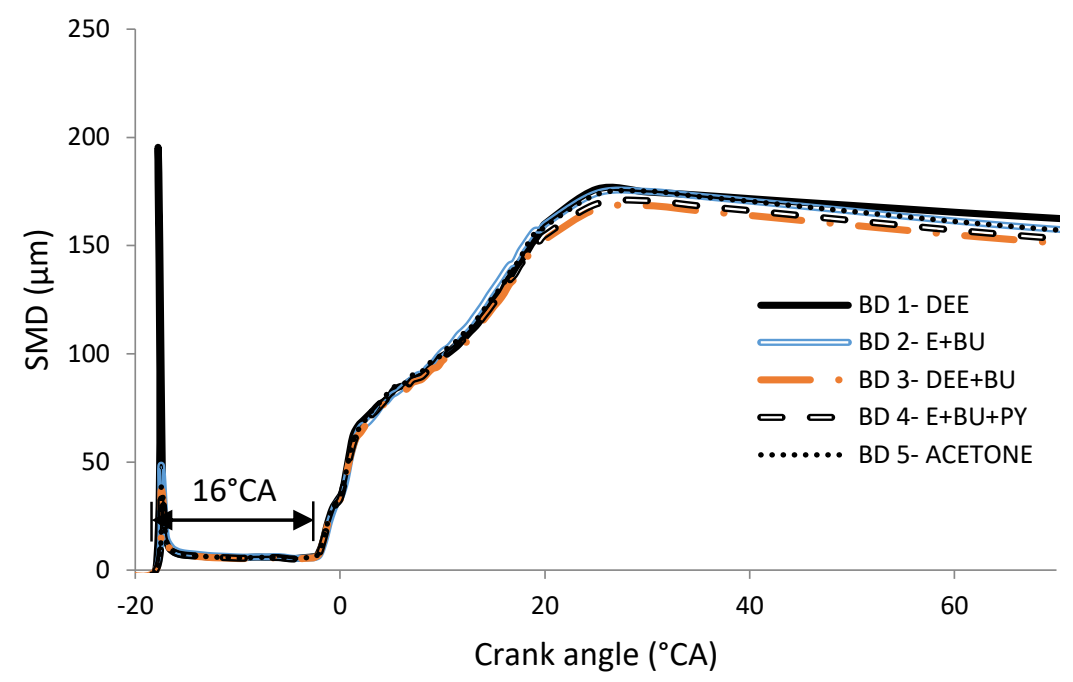

Fig. 5. SMD distributions of all biodiesel samples

\subsubsection{In-cylinder pressure and heat release rate (HRR)}

The variation of in-cylinder pressure with crank angle for biodiesel with different additives are shown in Figure 6. It is observed that the highest peak pressure value is BD1 with high pressure value of $7.74 \mathrm{MPa}$ whereas there is just a $0.1 \%$ different when comparing with BD3. This value indicates that these mixture produces the highest quality combustion compared to others. The higher volatility and lower viscosity of diethyl ether in BD1 results in more premixed air-fuel mixture in the ignition delay which improves the peak cylinder pressure, while the peak cylinder pressure of BD1 is almost similar to that of BD3. The peak cylinder pressure of BD3 is slightly lower may due to the longer ignition delay of $n$-butanol added as additional additive as a result of reduced cetane number. The peak cylinder pressure for BD2 and BD4 have attains a lower value comparing to BD1 and BD3. The reason can be explained is due to the higher latent heat value and lower cetane number of ethanol. Also, the pressure for both BD4 and BD5 are lowest among all samples and they tend to have the same trend to each other.

As observed from Figure 7 that heat release rate with crank angle followed a similar pattern for all different type of additives added into PME. Since fuel vaporization starts during ignition delay, a very small negative heat release is observed at the beginning, before the start of combustion, and then the heat release rate becomes positive. The ignition time is the start of heat release during combustion. The time interval from the beginning of heat release to the end of the heat release can be referred to as the total combustion period. On the other hand, the higher volatility and lower latent heat value of diethyl ether lead to a larger amount of fuel accumulation in the combustion chamber at the time of the combustion stage, leading to a higher rate of heat release for BD1. With the addition of high oxygen content additive such as n-butanol for $\mathrm{BD} 3$, the heat release heat rate increased for about $2 \%$ compare to BD1. The combustion heat release is higher for BD1 and BD3 owing to higher volatility of diethyl ether and butanol and better mixing with air, especially for BD3. The addition of higher oxygen content and high volatility fuels, such as diethyl ether and ethanol, can be a promising technique for using biodiesel/diesel blend efficiently in diesel engines without any modifications in the engine. However, the graph indicates that the peak cylinder pressure which contain diethyl ethers (BD1 and BD3) surpasses the biodiesel with ethanol (BD2 and BD4) by almost $9.67 \%$ before suddenly dipping down. 
Both results of pressure in cylinders and HRR found that additive DEE and butanol in PME in the mixture increased the pressure in the cylinder and HRR. This situation proves that the best content to use in producing achievements the best combustion is BD-3.

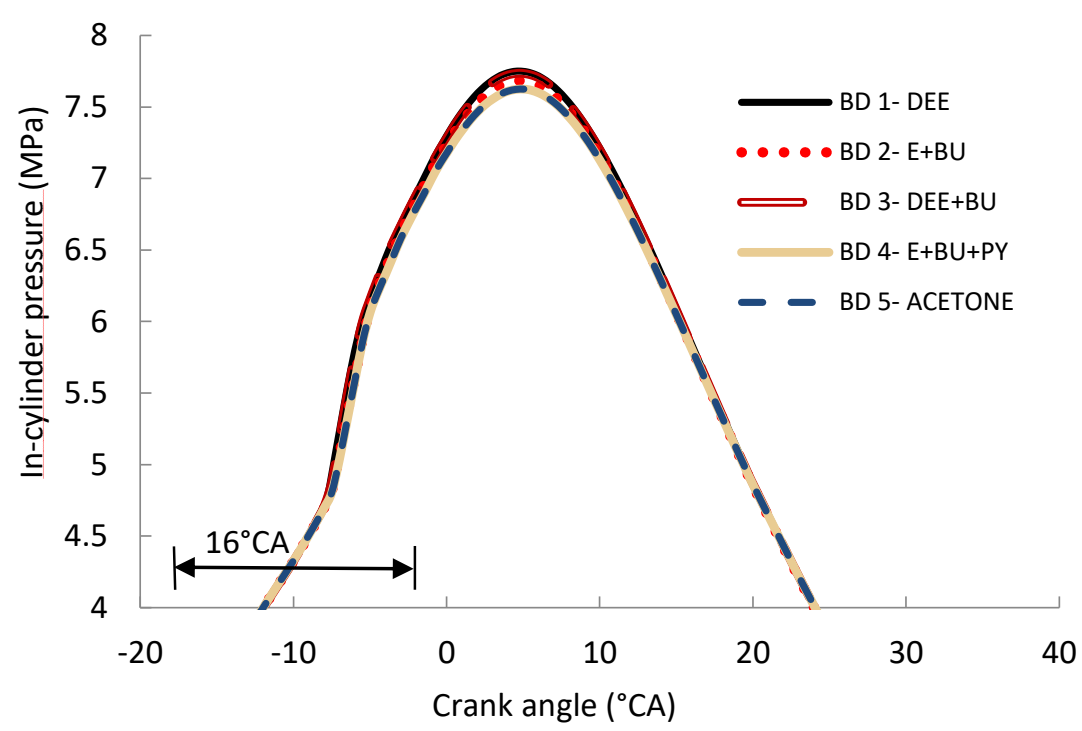

Fig. 6. In-cylinder pressure of all biodiesel samples at 1600 RPM

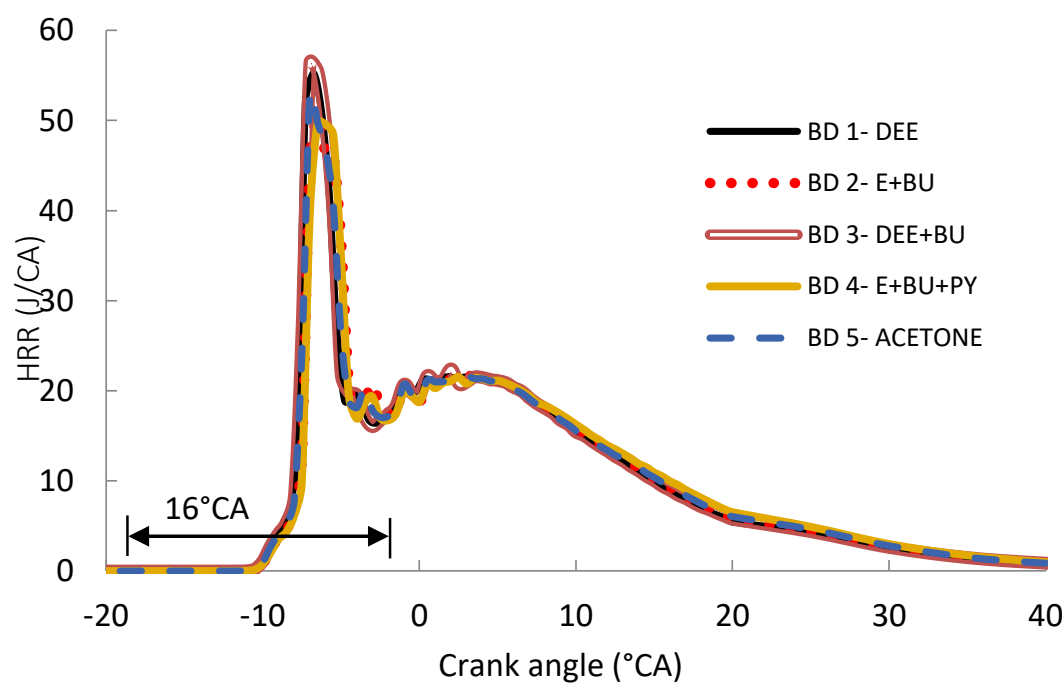

Fig. 7. Heat release rate (HRR) of all biodiesel samples at 1600 RPM

\subsection{Effect of Biodiesel with Additives on $\mathrm{No}_{x}, \mathrm{HC}, \mathrm{CO}_{2}$ and CO Emissions at $1600 \mathrm{RPM}$}

Figure 8 shows the emission of $\mathrm{NOx}, \mathrm{HC}, \mathrm{CO}_{2}$ and $\mathrm{CO}$ against the crank angle of biodiesel with additives at 1600 RPM engine speed. NOx emissions are sensitive to oxygen content, adiabatic flame temperature and spray characteristics. BD1, BD2, BD4 and BD5 show very slight change in NOx emissions among them while there was a decrease of NOx with BD3 is more significant. This indicates that increase in the oxygen content of biodiesel activates the formation of NOx resulting from the oxygen reaction with nitrogen. Normally, a more complete combustion will get a higher combustion temperature, which will cause a high NOx formation. The evident increase of NOx for BD2 and BD4 may be due to its highest oxygen content of ethanol, which should be the dominant factor for 
increasing NOx emissions. On the other hand, results showed that an addition n-butanol on BD3 has a counter effect on NOx emission and thereby decreased it by about $29.8 \%$ in comparison to BD1. This result has established the fact that $n$-butanol has the superior latent heat of vaporization and heightened the physicochemical properties of the mixtures that allowed the engine to operate smoothly without much engine modification.

Incomplete combustion products of $\mathrm{HC}$ emissions increased significantly with the additional of nbutanol in BD3, even though diethyl ether enriched the oxygen content in the fuel for BD1 and result the emission of $\mathrm{HC}$ is the highest among all sample. The reason for the increase of $\mathrm{HC}$ emission is $\mathrm{n}$ butanol has a lower boiling point and the evaporation characteristics are good. Besides, diethyl ether being volatile helps the evaporation of fuel and made the fuel slip into the cylinder and accumulation of fuel particles leading to improper air and fuel ratio. In addition, this study shows that the emission $\mathrm{HC}$ for BD4 and BD5 are the lowest and most likely to have the same amount of $\mathrm{HC}$ emission throughout the whole combustion process.

Carbon monoxide (CO) is the most common type of fatal air poisoning in many countries. It is colourless, odourless and tasteless, but highly toxic gas. In a complete cycle of internal combustion engines, $\mathrm{CO}$ emissions are generated as an intermediate combustion product and is formed mainly due to incomplete combustion of fuel. If combustion is complete, $\mathrm{CO}$ is converted to $\mathrm{CO}_{2}$. If the combustion is incomplete due to shortage of air or due to low gas temperature, CO will be formed. This condition causes the oxygen to react with all the carbon and this happens at high temperatures.

As showed in the graphs are the $\mathrm{CO}$ and $\mathrm{CO}_{2}$ emissions throughout the process for different tested biodiesel with respect to crank angle. The research found that the additional of $n$-butanol in diethyl ether with PME greatly reduces the percentage of emissions $\mathrm{CO}$ and $\mathrm{CO}_{2}$. It is shown the different in $\mathrm{CO}$ and $\mathrm{CO}_{2}$ emission between BD1 and BD3 are huge with a percentage difference of $18 \%$ and $6.2 \%$ respectively. This matter as low viscosity of $n$-butanol partially compensates the negative impact of higher viscosity of PME. Therefore, $\mathrm{CO}$ and $\mathrm{CO}_{2}$ emission is greatly reduced. It also has a higher oxygen content help in complete oxidation of modified blends, and therefore reduced $\mathrm{CO}$ and $\mathrm{CO}_{2}$ emissions.
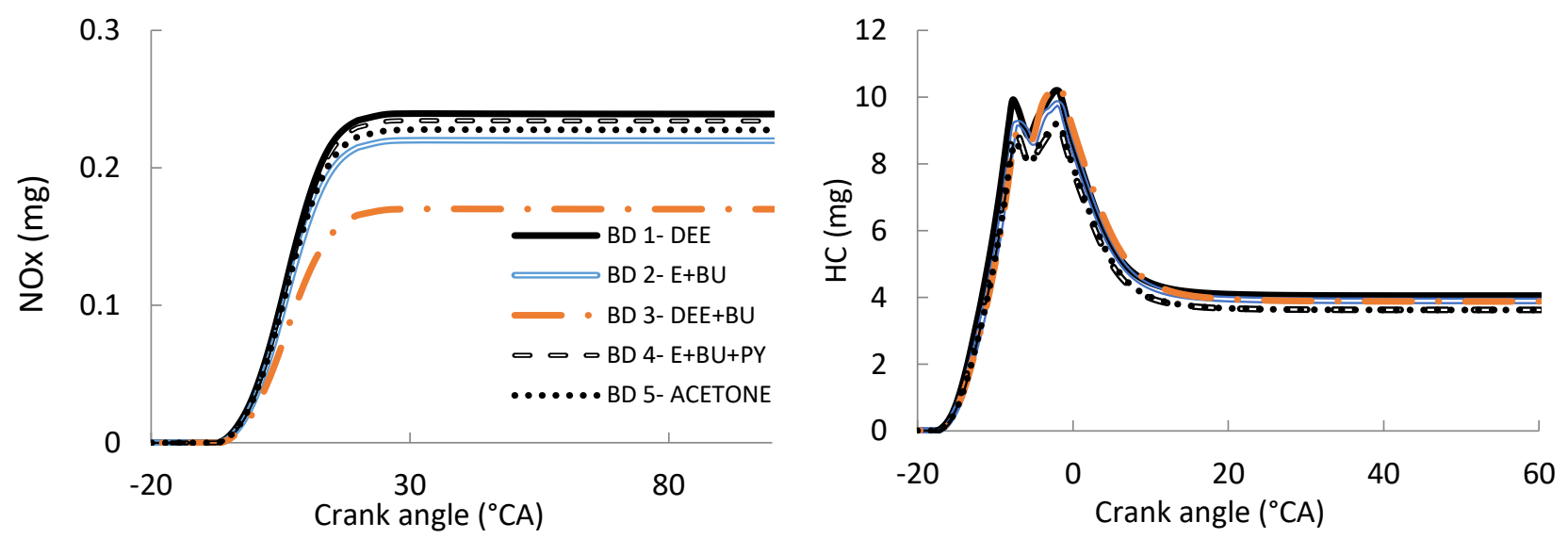

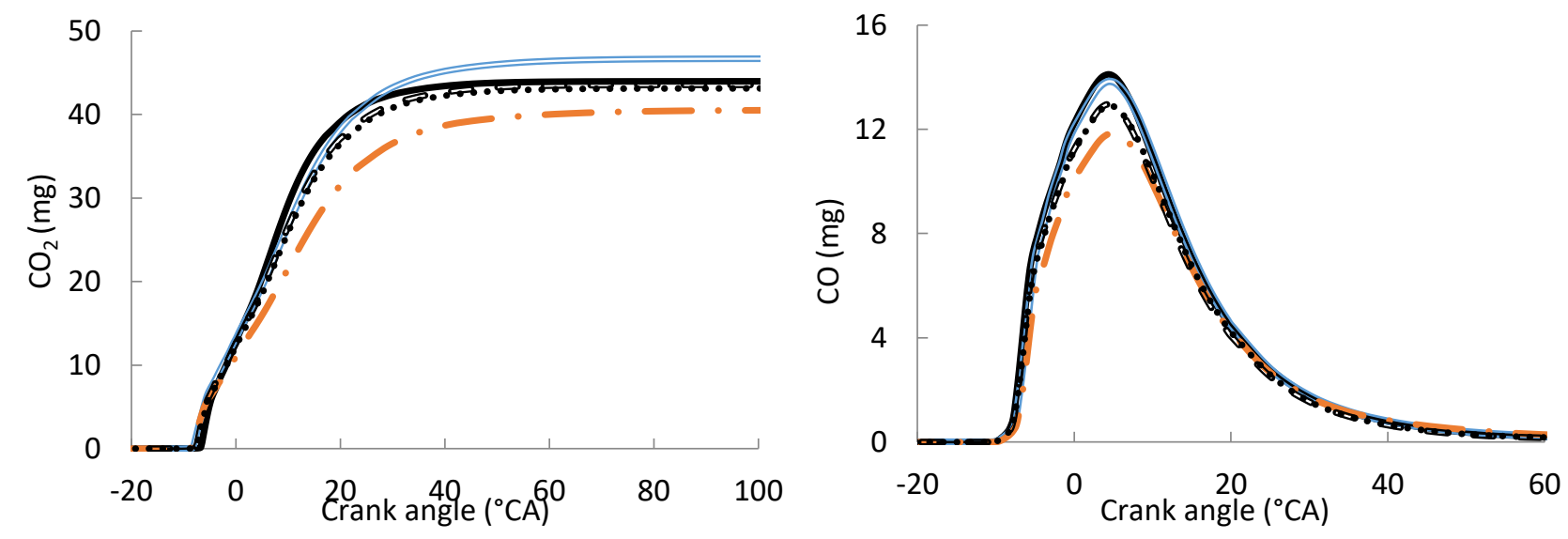

Fig. 8. Emission graphs of all biodiesel samples at 1600 RPM

\subsection{Effect of Biodiesel with Additives on $\mathrm{No}_{x}, \mathrm{HC}, \mathrm{CO}$ and $\mathrm{CO}_{2}$ Emissions at Various Engine Speed}

Of all the biodiesel samples (BD1, BD2, BD3, BD4, and BD5), BD3 with additives combination of diethyl ether and $n$-butanol is found to be the most optimum to blend with PME with regard to performance, combustion and emission characteristics. Therefore, in this present investigation the performance on NOx, HC, $\mathrm{CO}$ and $\mathrm{CO} 2$ emissions for BD3 is analysed at different engine speeds.

Figure 9 shows the NOx emission graph of BD3 against crank angles at different engine speeds of 900 RPM, 1600 RPM and 2400 RPM. The results of the study found that combustion of BD3 at low engine speeds released higher NOx emissions. As illustrated showed $\mathrm{HC}$ emission graph against the crank angle of BD3 at different engine speeds where the $\mathrm{HC}$ emissions of BD3 at high speed release higher $\mathrm{HC}$ emissions. This is due to the reaction of the air and fuel not being able to complete completely and producing excess hydrogen carbon. CO2 emissions are released rapidly at 900 RPM at the beginning of ignition and it remain the same value with engine operates at the speeds of 1600 RPM at the end of combustion. At the same time, CO emissions are found to be decreasing with increasing engine speed. After the combustion, $\mathrm{CO}$ emissions reduced drastically. Combustion at a lower engine speeds released higher $\mathrm{CO}$ emissions of $12.69 \mathrm{mg}$. This is due to insufficient oxygen content and low temperature in the cylinder can produce high $\mathrm{CO}$ emission reactions at low engine speeds
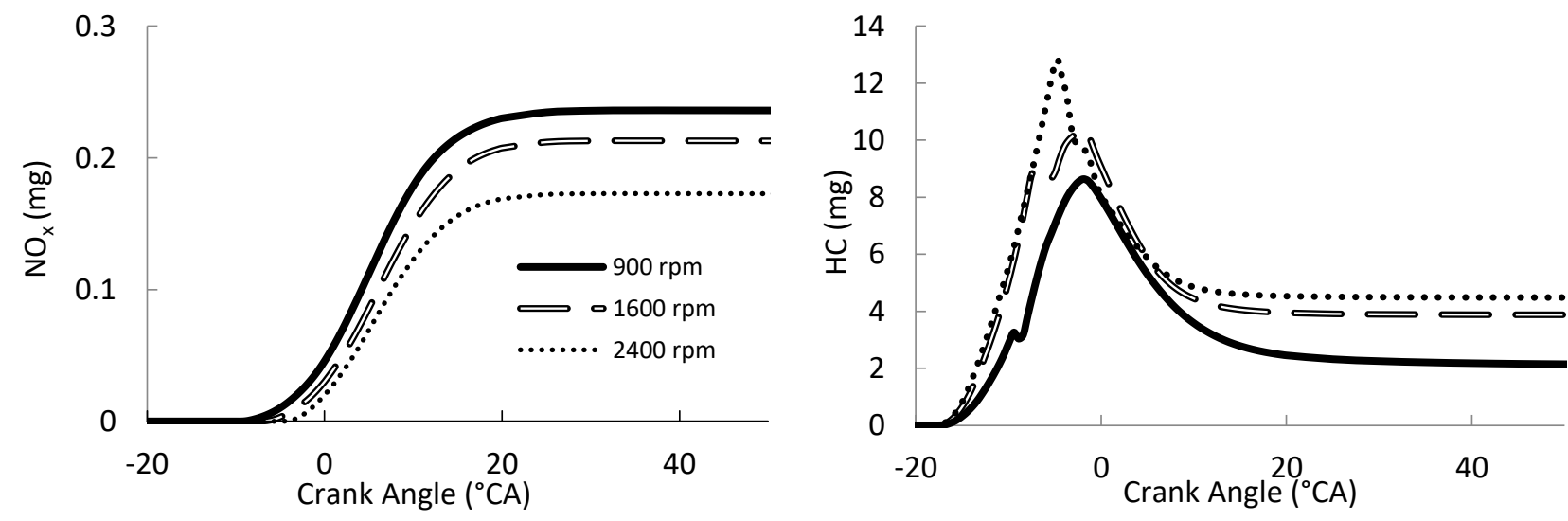

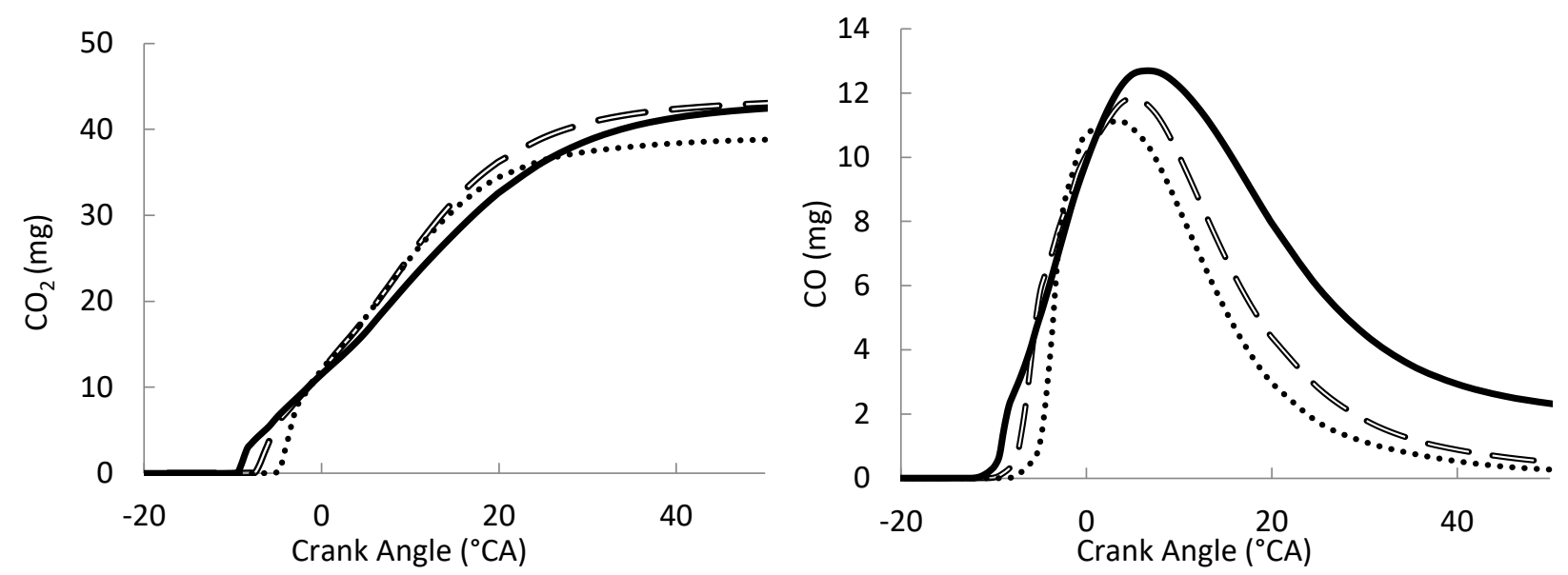

Fig. 9. Emission graphs of $\mathrm{BD} 3$ at various engine speeds

\section{Conclusions}

The comprehensive study framed the effect of additives on the biodiesel properties, performance and emissions when used as an alternative fuel in the conventional diesel engine. Different additives with more oxygen contents are available. If such type of additives added into the blends of biodiesel, they can enhance the quality of combustion and leads to complete combustion. Engine performance and emissions were evaluated and simulated using CONVERGE CFD, the following conclusions are drawn from the study:

I. Both results of the in-cylinder pressure and HRR were record the highest among all the biodiesel for BD3 with the value of $7.74 \mathrm{MPa}$ and $55.26 \mathrm{~J} /{ }^{\circ} \mathrm{CA}$. This is due to the lower viscosity and higher volatility of diethyl ether and butanol; the more fuel air mixture is formed which results in a strong burning phase and gives rise to the cylinder pressure.

II. The combination of diethyl ether and n-butanol as an additive can be helpful in reducing various emissions except $\mathrm{HC}$ from the exhausts and its addition in biodiesels in future would make a good prospective fuel. With diethyl ether and n-butanol additional to BD3 can produced lesser $\mathrm{CO}, \mathrm{CO} 2, \mathrm{NOx}$ but higher $\mathrm{HC}$ emissions when comparing with others additive in the samples.

III. From the comparison at the various engine speeds, combustion of BD3 at low engine speeds released higher NOx and CO emissions.

\section{Acknowledgement}

The authors would like to thank Universiti Kebangsaan Malaysia for supporting this research with grant GUP-2018-099.

\section{References}

[1] Imtenan, Sayeed, H. H. Masjuki, Mahendra Varman, M. A. Kalam, M. I. Arbab, H. Sajjad, and SM Ashrafur Rahman. "Impact of oxygenated additives to palm and jatropha biodiesel blends in the context of performance and emissions characteristics of a light-duty diesel engine." Energy Conversion and Management 83 (2014): 149-158. https://doi.org/10.1016/j.enconman.2014.03.052

[2] Khalid, Amir, Shahrul Azmir Osman, M. Jaat, Norrizal Mustaffa, Siti Mariam Basharie, and Bukhari Manshoor. "Performance and emissions characteristics of diesel engine fuelled by biodiesel derived from palm oil." In Applied Mechanics and Materials, vol. 315, pp. 517-522. Trans Tech Publications Ltd, 2013. https://doi.org/10.4028/www.scientific.net/AMM.315.517 
[3] Fangsuwannarak, Karoon, and Kittichai Triratanasirichai. "Effect of metalloid compound and bio-solution additives on biodiesel engine performance and exhaust emissions." American journal of applied sciences 10, no. 10 (2013): 1201.

https://doi.org/10.3844/ajassp.2013.1201.1213

[4] Lapuerta, Magín, Octavio Armas, Juan José Hernández, and Athanasios Tsolakis. "Potential for reducing emissions in a diesel engine by fuelling with conventional biodiesel and Fischer-Tropsch diesel." Fuel 89, no. 10 (2010): 31063113.

https://doi.org/10.1016/j.fuel.2010.05.013

[5] Monirul, I. M., H. H. Masjuki, M. A. Kalam, M. H. Mosarof, N. W. M. Zulkifli, Y. H. Teoh, and H. G. How. "Assessment of performance, emission and combustion characteristics of palm, jatropha and Calophyllum inophyllum biodiesel blends." Fuel 181 (2016): 985-995.

https://doi.org/10.1016/i.fuel.2016.05.010

[6] Yilmaz, Nadir, and Byron Morton. "Effects of preheating vegetable oils on performance and emission characteristics of two diesel engines." Biomass and Bioenergy 35, no. 5 (2011): 2028-2033.

https://doi.org/10.1016/j.biombioe.2011.01.052

[7] Gomma MGG, Alimin AJ, and Kamarudin KA. "Trade-off between NOx and Smoke Emissions Using EGR for a C.I Engine Fuelled with Jatropha Biodiesel Blends." Journal of Applied Sciences 11, no. 11 (2010): 1987-1993.

https://doi.org/10.3923/jas.2011.1987.1993

[8] Xue, Jinlin, Tony E. Grift, and Alan C. Hansen. "Effect of biodiesel on engine performances and emissions." Renewable and Sustainable energy reviews 15, no. 2 (2011): 1098-1116.

https://doi.org/10.1016/i.rser.2010.11.016

[9] Obed MA, Mamat R, and Faizal CKM. "Review of the Effects of Additives on Biodiesel Properties, Performance, and Emission Features." Renewable and Sustainable Energy Review 5, no, 1 (2013).

https://doi.org/10.1063/1.4792846

[10] Taib, Norhidayah Mat, Mohd Radzi Abu Mansor, Wan Mohd Faizal Wan Mahmood, Fais Ahmad Shah, and Nik Rosli Nik Abdullah. "Investigation of diesel-ethanol blended fuel properties with palm methyl ester as co-solvent and blends enhancer." In MATEC Web of Conferences, vol. 90, p. 01080. EDP Sciences, 2017. https://doi.org/10.1051/matecconf/20179001080

[11] Swaminathan, C., and J. Sarangan. "Performance and exhaust emission characteristics of a $\mathrm{Cl}$ engine fueled with biodiesel (fish oil) with DEE as additive." biomass and bioenergy 39 (2012): 168-174.

https://doi.org/10.1016/i.biombioe.2012.01.001

[12] Fang, Qiang, Junhua Fang, Jian Zhuang, and Zhen Huang. "Effects of ethanol-diesel-biodiesel blends on combustion and emissions in premixed low temperature combustion." Applied Thermal Engineering 54, no. 2 (2013): 541-548. https://doi.org/10.1016/j.applthermaleng.2013.01.042

[13] Sukjit, E., Jose Martin Herreros, J. Piaszyk, K. D. Dearn, and A. Tsolakis. "Finding synergies in fuels properties for the design of renewable fuels-Hydroxylated biodiesel effects on butanol-diesel blends." Environmental science \& technology 47, no. 7 (2013): 3535-3542.

https://doi.org/10.1021/es400131j

[14] Altun, Sehmus, Cengiz Oner, Fevzi Yasar, and Hamit Adin. "Effect of $n$-butanol blending with a blend of diesel and biodiesel on performance and exhaust emissions of a diesel engine." Industrial \& engineering chemistry research 50, no. 15 (2011): 9425-9430. https://doi.org/10.1021/ie201023f

[15] Khan, Iftikhar Ahmed, S. K. Singh, Ashok Kumar Yadav, Uttam Ghosh, and Durgesh Sharma. "Enhancement in the performance of a diesel engine fuelled with Pongamia methyl ester and $n$-butanol as oxygenated additive." International Journal of Ambient Energy 40, no. 8 (2019): 842-846.

https://doi.org/10.1080/01430750.2018.1437559

[16] Guarieiro, Lílian Lefol Nani, Egídio Teixeira de Almeida Guerreiro, Keize Katiane dos Santos Amparo, Victor Bonfim Manera, Ana Carla D. Regis, Aldenor Gomes Santos, Vitor P. Ferreira, Danilo J. Leão, Ednildo A. Torres, and Jailson B. de Andrade. "Assessment of the use of oxygenated fuels on emissions and performance of a diesel engine." Microchemical Journal 117 (2014): 94-99.

https://doi.org/10.1016/i.microc.2014.06.004

[17] Sezer, Ismet. "Thermodynamic, performance and emission investigation of a diesel engine running on dimethyl ether and diethyl ether." International Journal of Thermal Sciences 50, no. 8 (2011): 1594-1603.

https://doi.org/10.1016/j.ijthermalsci.2011.03.021

[18] Puhan, Sukumar, N. Saravanan, G. Nagarajan, and N. Vedaraman. "Effect of biodiesel unsaturated fatty acid on combustion characteristics of a DI compression ignition engine." Biomass and Bioenergy 34, no. 8 (2010): 10791088. 
https://doi.org/10.1016/j.biombioe.2010.02.017

[19] Taib, Norhidayah Mat, Mohd Radzi Abu Mansor, W. M. F. W. Mahmood, and Nik Rosli Abdullah. "Simulation study of combustion characteristics of diesel-ethanol-palm oil methyl ester blends in diesel engine." Journal of Advanced Research in Fluid Mechanics and Thermal Sciences 44, no. 1 (2018): 149-156.

[20] Mat Taib, Norhidayah, Mohd Radzi Abu Mansor, and Wan Mohd Faizal Wan Mahmood. "Modification of a Direct Injection Diesel Engine in Improving the Ignitability and Emissions of Diesel-Ethanol-Palm Oil Methyl Ester Blends." Energies 12, no. 14 (2019): 2644.

https://doi.org/10.3390/en12142644 